\title{
Role of radiological parameters in predicting overall shunt outcome after ventriculoperitoneal shunt insertion in pediatric patients with obstructive hydrocephalus
}

\author{
Devi Prasad Patra, MD, MCh, Shyamal C. Bir, MD, PhD, Tanmoy K. Maiti, MD, MCh, \\ Piyush Kalakoti, MD, Hugo Cuellar, MD, PhD, Bharat Guthikonda, MD, Hai Sun, MD, PhD, \\ Christina Notarianni, MD, and Anil Nanda, MD, MPH \\ Department of Neurosurgery, Louisiana State University Health Sciences Center, Shreveport, Louisiana
}

\begin{abstract}
OBJECTIVE Despite significant advances in the medical field and shunt technology, shunt malfunction remains a nightmare of pediatric neurosurgeons. In this setting, the ability to preoperatively predict the probability of shunt malfunction is quite compelling. The authors have compared the preoperative radiological findings in obstructive hydrocephalus and the subsequent clinical course of the patient to determine any association with overall shunt outcome.

METHODS This retrospective study included all pediatric patients (age $<18$ years) who had undergone ventriculoperitoneal shunt insertion for obstructive hydrocephalus. Linear measurements were taken from pre- and postoperative CT or MRI studies to calculate different indices and ratios including Evans' index, frontal horn index (FHI), occipital horn index (OHI), frontooccipital horn ratio (FOHR), and frontooccipital horn index ratio (FOIR). Other morphological features such as bi- or triventriculomegaly, right-left ventricular symmetry, and periventricular lucency (PVL) were also noted. The primary clinical outcomes that were reviewed included the need for shunt revision, time interval to first shunt revision, frequency of shunt revisions, and revision-free survival.
\end{abstract}

RESULTS A total of 121 patients were eligible for the analysis. Nearly half of the patients $(47.9 \%)$ required shunt revision. The presence of PVL was associated with lower revision rates than those in others ( $39.4 \%$ vs $58.2 \%, p=0.03$ ). None of the preoperative radiological indices or ratios showed any correlation with shunt revision. Nearly half of the patients with shunt revision required early revision (<90 days of primary surgery). The reduction in the FOHR was high in patients who required early shunt revision $(20.16 \%$ in patients with early shunt revision vs $6.4 \%$ in patients with late shunt revision, $p=0.009$ ). Nearly half of the patients $(48.3 \%)$ requiring shunt revision ultimately needed more than one revision procedure. Greater occipital horn dilation on preoperative images was associated with a lower frequency of shunt revision, as dictated by a high $\mathrm{OHI}$ and a low FOIR in patients with a single shunt revision as compared with those in patients who required multiple shunt revisions ( $p=0.029$ and 0.009 , respectively). The mean follow-up was 49.9 months. Age was a significant factor affecting shunt revision-free survival. Patients younger than 6 months of age had significantly less revision-free survival than the patients older than 6 months (median survival of 10.1 vs 94.1 months, $p=0.004$ ).

CONCLUSIONS Preoperative radiological linear indices and ratios do not predict the likelihood of subsequent shunt malfunction. However, patients who required early shunt revision tended to have greater reductions in ventricular volumes on postoperative images. Therefore a greater reduction in ventricular volume is not actually desirable, and a ventricular volume high enough to reduce intracranial pressure is instead to be aimed at for long-term shunt compliance.

http://thejns.org/doi/abs/10.3171/2016.8.FOCUS16263

KEY WORDS pediatric hydrocephalus; obstructive; radiological; indices and ratios; ventricular peritoneal; shunt; outcome

$\mathrm{O}$ BSTRUCTIVE hydrocephalus is one of the most common diagnoses encountered in pediatric clinical practice. Mechanical shunting by placement of a ventriculoperitoneal (VP) shunt has traditionally been the treatment of choice in these patients. Recently, endoscopic procedures such as third ventriculostomy with or without choroid plexus cauterization have been considered as the first-line treatment or, at times, the first shunt failure. However, VP shunt insertion has continued to be the solely practiced method in many parts of the world, especially

ABBREVIATIONS $\mathrm{FHI}=$ frontal horn index; FOHR = frontooccipital horn ratio; FOIR = frontooccipital horn index ratio; ICP = intracranial pressure; $\mathrm{OHI}=0 \mathrm{cccipital}$ horn index; $P V L=$ periventricular lucency; $V P=$ ventriculoperitoneal.

SUBMITTED June 27, 2016. ACCEPTED August 5, 2016.

INCLUDE WHEN CITING DOI: 10.3171/2016.8.FOCUS16263. 
developing countries. Other forms of mechanical shunting such as with ventriculopleural, ventriculoatrial, and lumboperitoneal shunts are mostly reserved as a measure of last resort for difficult or complicated cases. Shunt malfunction in hydrocephalic pediatric patients has continued to be a large social and financial burden to the country with an average estimate of nearly $40 \%$ of patients requiring shunt revision within the first year itself. ${ }^{13,15,16}$ Despite significant advances in the medical field, shunt malfunction remains a nightmare of the pediatric neurosurgeon. Even programmable shunts, which were presumed to be an effective solution to shunt malfunction, do not reduce the shunt revision rate, as estimated in our previous study. ${ }^{13}$ In this setting, the ability to preoperatively predict the probability of shunt malfunction is an implicit desire of pediatric neurosurgeons. In this study, we compared the preoperative radiological findings in obstructive hydrocephalus with the subsequent clinical course of the patient to determine any associations with overall shunt outcome.

\section{Methods}

This retrospective study included all pediatric patients with an age $<18$ years who had undergone VP shunt surgery for obstructive hydrocephalus at our institute between January 2004 and January 2016. Clinical and radiological data including follow-up were reviewed from hospital records after we had obtained local institutional review board approval and complied with Health Insurance Portability and Accountability Act (HIPAA) regulations.

\section{Radiological Data Acquisition}

Preoperative and postoperative CT or MRI studies (MRI was preferred over CT) were reviewed, and measurements were taken using the hospital-based picture archiving and communication system (PACS). Availability of paired preoperative and postoperative images was a significant concern, and unavailability led to exclusion from analysis. Patients who underwent surgery based on cranial ultrasound were excluded from the study. Measurements were taken using the "measurement tool" of the PACS 4.0 software (Centricity Radiology RA1000, GE Healthcare). Linear indices were calculated per the formulas given in Table 1 and Fig. 1. Other radiological factors were also noted, including bi- or triventriculomegaly, ventricular symmetry (right-left symmetry), and the presence or absence of periventricular lucency (PVL). Ventricular asymmetry was documented when the difference in the diameters of both sides of the ventricles was more than $2 \mathrm{~mm} .{ }^{5}$

\section{Clinical Data Acquisition}

The primary clinical outcomes that were reviewed included the need for shunt revision, time interval to first shunt revision after primary surgery, total number of shunt revisions, and revision-free survival. The latter was calculated based on the interval between primary surgery and the first shunt revision. In patients who did not require shunt revision, it was calculated based on the maximum available follow-up time. These outcomes were correlated with the preoperative radiological parameters and indices.
TABLE 1. Description of radiological linear indices and ratios

\begin{tabular}{|c|c|c|}
\hline Indices \& Ratios & Calculation Method & Formula* \\
\hline Evans' index & $\begin{array}{l}\text { Maximum frontal horn diameter } \\
\text { divided by maximum cranial } \\
\text { diameter in that plane }\end{array}$ & $\mathrm{a} / \mathrm{e}$ \\
\hline $\begin{array}{l}\text { Frontal horn } \\
\quad \text { index (FHI) }\end{array}$ & $\begin{array}{l}\text { Maximum frontal horn diameter } \\
\text { divided by maximum cranial } \\
\text { diameter at frontal horn level }\end{array}$ & $a / b$ \\
\hline $\begin{array}{l}\text { Occipital horn } \\
\text { index }(\mathrm{OHI})\end{array}$ & $\begin{array}{l}\text { Maximum occipital horn diameter } \\
\text { divided by maximum cranial } \\
\text { diameter at occipital horn level }\end{array}$ & $c / d$ \\
\hline $\begin{array}{l}\text { Frontooccipital } \\
\text { horn ratio } \\
\text { (FOHR) }\end{array}$ & $\begin{array}{l}\text { (Maximum frontal horn diameter } \\
+ \text { maximum occipital horn } \\
\text { diameter) divided by } 2 \times \text { the } \\
\text { biparietal diameter }\end{array}$ & $(a+c) / 2 e$ \\
\hline $\begin{array}{l}\text { Frontooccipital } \\
\text { horn index } \\
\text { ratio (FOIR) }\end{array}$ & $\begin{array}{l}\text { Frontal horn index divided by } \\
\text { occipital horn index }\end{array}$ & $\begin{array}{l}(\mathrm{a} / \mathrm{b}) /(\mathrm{c} / \mathrm{d})=\mathrm{ad} / \\
\mathrm{bc}\end{array}$ \\
\hline $\begin{array}{l}\text { Reduction } \\
\text { FOHR (\%) }\end{array}$ & $\begin{array}{l}\text { Reduction in FOHR on postop } \\
\text { images as a percentage of } \\
\text { preop FOHR }\end{array}$ & $\begin{array}{l}\text { [(preop FOHR } \\
\quad \text { - postop } \\
\text { FOHR)/preop } \\
\text { FOHR] } \times 100\end{array}$ \\
\hline
\end{tabular}

* Refer to Fig. 1.

\section{Statistical Methods}

Statistical analysis was done using SPSS software (version 24.0, IBM Corp). The mean values of the linear indi-

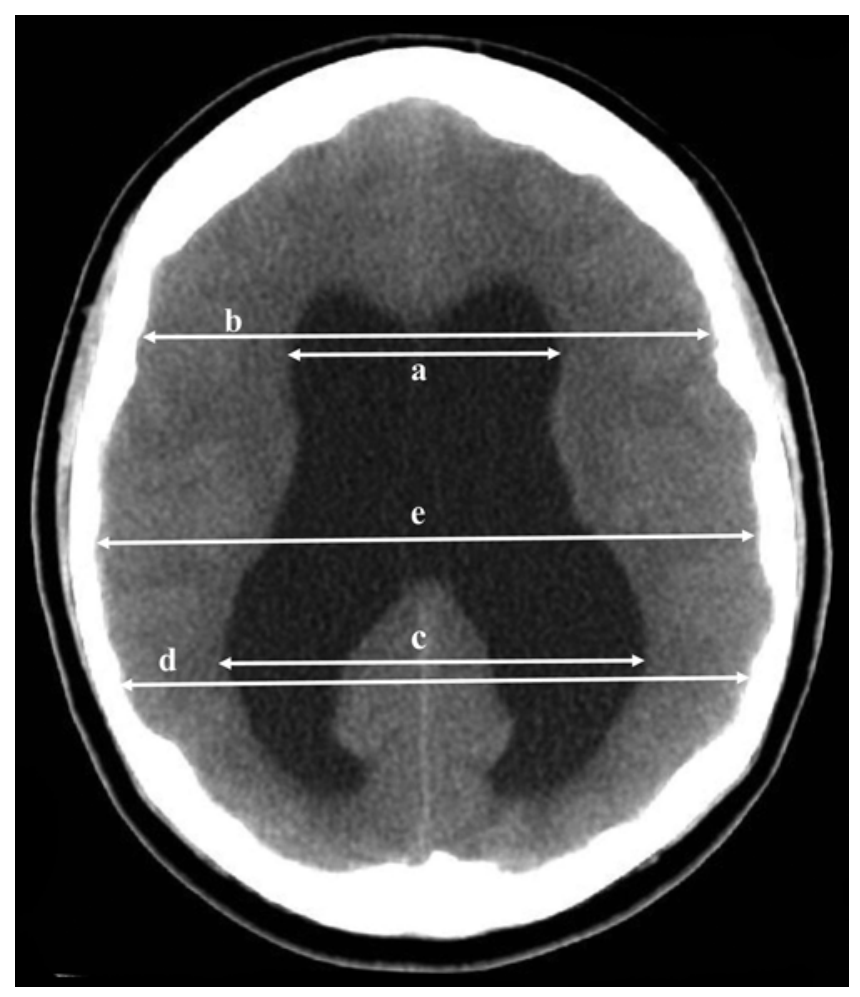

FIG. 1. Linear measurements in the cranial CT. $a=$ maximal diameter of the frontal horn; $b=$ maximal cranial diameter at the level of the frontal horn; $c=$ maximal diameter of the occipital horn; $d=$ maximal cranial diameter at the level of the occipital horn; $e=$ maximal cranial diameter (biparietal diameter). 
ces and ratios were compared with the different outcome groups by using an independent sample t-test. A comparison of the different groups was done using the chi-square test and ANOVA. A multivariate analysis was conducted for all outcomes, considering all radiological indices as covariates. Shunt revision-free survival was calculated and plotted using the Kaplan-Meier method. Mean values were expressed with the standard error of the mean. A p value $<0.05$ was considered statistically significant.

\section{Results}

A total of 273 patients were treated for pediatric hydrocephalus at our institute between January 2004 and January 2016. Of this total, 172 patients had obstructive hydrocephalus from various etiologies. Forty-seven patients were excluded because comparative radiological studies were unavailable, and 4 patients were excluded for inadequate clinical data; thus, 121 patients were included in our analysis. Demographics on the patients and their outcomes have been listed in Table 2. All patients underwent VP shunt placement as the primary procedure. Postoperative CT or MRI studies were available at various intervals (median interval 5 days, range 1-60 days, approximately $90 \%$ of the scans had been obtained within 1 month). Postoperative indices were calculated, including the critical frontooccipital horn ratio (FOHR). Reduction of the FOHR was calculated as a percentage of the initial FOHR (Table 1).

\section{Factors Affecting Shunt Revision}

Nearly half of the patients (47.9\%) required shunt revision. The presence of PVL on the preoperative images was significantly associated with lower revision rates in the univariate analysis $(39.4 \%$ vs $58.2 \%$ in the presence or absence of PVL, respectively, $p=0.03$ ), though it failed to reach a significant level in the multivariate analysis ( $\mathrm{p}$ $=0.11$; Table 3). Triventricular and symmetric ventricular enlargements more commonly led to shunt revision, though the difference was not statistically significant ( $p$ $=0.19$ and 0.059 , respectively). There was no significant difference between shunt revision rates among the different etiologies $(p=0.09)$. Similarly, the type of shunt did not show any influence on shunt revision rates $(\mathrm{p}=$ 0.33 ). None of the preoperative radiological indices or ratios showed any correlation with subsequent shunt revision in both univariate and multivariate analyses (Table 4). The postoperative reductions of FOHR were found to be similar in patients with or without shunt revision (13\% vs $12.1 \%$ respectively, $\mathrm{p}=0.39$ ).

\section{Factors Affecting the Shunt Revision Interval}

The median interval to the first shunt revision from the primary surgery was 99.5 days (range 12 days-7.7 years, approximately $90 \%$ of revisions occurred within 2 years). The shunt revision interval was stratified into 2 groups: early revision (within 90 days) or late revision (after 90 days). Nearly half of the patients with shunt revision required early revision. None of the factors such as etiology, bi- or triventricular dilation, ventricular symmetry,
TABLE 2. Characteristics and outcomes of 121 patients with obstructive hydrocephalus

\begin{tabular}{|c|c|}
\hline Parameter & Value \\
\hline Median age (range) & 6 mos (1 wk-17.8 yrs) \\
\hline \multicolumn{2}{|l|}{ Sex } \\
\hline Male & $68(56.2 \%)$ \\
\hline Female & $53(43.8 \%)$ \\
\hline \multicolumn{2}{|l|}{ Race } \\
\hline White & $54(44.6 \%)$ \\
\hline African American & $65(53.7 \%)$ \\
\hline Other & $2(1.6 \%)$ \\
\hline \multicolumn{2}{|l|}{ Diagnosis } \\
\hline $\begin{array}{l}\text { Congenital hydrocephalus (w/ spina bifida } \\
\text { or other congenital anomalies) }\end{array}$ & $38(31.4 \%)$ \\
\hline Aqueductal stenosis & $30(24.8 \%)$ \\
\hline Posthemorrhagic & $28(23.1 \%)$ \\
\hline Tumor & $21(17.4 \%)$ \\
\hline Postmeningitis & $1(0.8 \%)$ \\
\hline Posttraumatic & $3(2.5 \%)$ \\
\hline \multicolumn{2}{|l|}{ Radiological findings } \\
\hline \multicolumn{2}{|l|}{ Hydrocephalus pattern } \\
\hline Biventricular & $26(21.5 \%)$ \\
\hline Triventricular & $95(78.5 \%)$ \\
\hline \multicolumn{2}{|l|}{ PVL } \\
\hline Present & $66(54.5 \%)$ \\
\hline Absent & $55(45.4 \%)$ \\
\hline \multicolumn{2}{|l|}{ Ventricular symmetry } \\
\hline Symmetric dilation & $78(64.5 \%)$ \\
\hline Asymmetric dilation & $43(35.5 \%)$ \\
\hline \multicolumn{2}{|l|}{ Shunt type } \\
\hline Medium-pressure shunt & $65(53.7 \%)$ \\
\hline Low-pressure shunt & $38(31.4 \%)$ \\
\hline Programmable shunt & $18(14.9 \%)$ \\
\hline \multicolumn{2}{|l|}{ Shunt revision } \\
\hline Total no. of revisions & $58(47.9 \%)$ \\
\hline \multicolumn{2}{|l|}{ Frequency of revision } \\
\hline Once & $30(24.8 \%)$ \\
\hline Twice & $17(14 \%)$ \\
\hline More than twice & $11(9.1 \%)$ \\
\hline \multicolumn{2}{|l|}{ Interval from primary surgery } \\
\hline Early (w/in 3 mos) & $28(48.3 \%)$ \\
\hline Late (after 3 mos) & $30(51.7 \%)$ \\
\hline \multicolumn{2}{|l|}{ FU outcome } \\
\hline No complaints & $103(85.1 \%)$ \\
\hline $\begin{array}{l}\text { Associated morbidity (headache, blurring } \\
\text { of vision, developmental delay, etc.) }\end{array}$ & $15(12.4 \%)$ \\
\hline Death & $3(2.5 \%)$ \\
\hline
\end{tabular}

$\mathrm{FU}=$ follow-up 
TABLE 3. Factors affecting shunt revision in 58 patients with obstructive hydrocephalus

\begin{tabular}{|c|c|c|c|c|c|c|c|c|c|}
\hline \multirow[b]{2}{*}{ Factor } & \multicolumn{3}{|c|}{ Shunt Revision } & \multicolumn{3}{|c|}{ Revision Interval } & \multicolumn{3}{|c|}{ Revision Frequency } \\
\hline & Yes & No & $p$ Value & Early (<3 mos) & Late (>3 mos) & p Value & Single & Multiple & $p$ Value \\
\hline Ventricular dilation & & & 0.19 & & & 0.41 & & & 0.32 \\
\hline Biventricular & 10 & 16 & & 4 & 6 & & 4 & 6 & \\
\hline Triventricular & 48 & 47 & & 24 & 24 & & 26 & 22 & \\
\hline Ventricular symmetry & & & 0.059 & & & 0.44 & & & 0.14 \\
\hline Symmetric & 42 & 36 & & 21 & 21 & & 24 & 18 & \\
\hline Asymmetric & 16 & 27 & & 7 & 9 & & 6 & 10 & \\
\hline PVL & & & 0.03 & & & 0.51 & & & 0.29 \\
\hline Present & 26 & 40 & & 13 & 13 & & 15 & 11 & \\
\hline Absent & 32 & 23 & & 15 & 17 & & 15 & 17 & \\
\hline Diagnosis & & & 0.09 & & & 0.20 & & & 0.38 \\
\hline Congenital & 19 & 19 & & 6 & 13 & & 10 & 9 & \\
\hline Aqueductal stenosis & 19 & 11 & & 11 & 8 & & 7 & 12 & \\
\hline Posthemorrhagic & 13 & 15 & & 8 & 5 & & 8 & 5 & \\
\hline Tumor & 5 & 16 & & 3 & 2 & & 3 & 2 & \\
\hline Other & 2 & 2 & & 0 & 2 & & 2 & 0 & \\
\hline Shunt type & & & 0.33 & & & 0.14 & & & 0.68 \\
\hline Medium pressure & 28 & 37 & & 16 & 12 & & 15 & 13 & \\
\hline Low pressure & 22 & 16 & & 7 & 15 & & 10 & 12 & \\
\hline Programmable & 8 & 10 & & 5 & 3 & & 5 & 3 & \\
\hline
\end{tabular}

presence of PVL, or shunt type significantly affected the shunt revision interval (Table 3). Interestingly, preoperative FOHR had a significant association with the shunt revision interval (mean FOHR 0.58 in patients with early shunt revision vs 0.53 in those with late shunt revision, $\mathrm{p}$ $=0.049$; Table 5). However, the parameter with the most significant association with the shunt revision interval was the reduction in FOHR $(20.16 \%$ in patients with early shunt revision vs $6.4 \%$ in patients with late shunt revision, $\mathrm{p}=0.009)$. This significant difference held true in the multivariate analysis too $(\mathrm{p}=0.037)$.

\section{Factors Affecting the Frequency of Shunt Revision}

Nearly half of the patients $(48.3 \%)$ requiring shunt revision ultimately needed more than one revision procedure (Table 1). Preoperative OHI and FOIR had significant associations with shunt revision frequency $(\mathrm{p}=0.029$ and 0.009 , respectively) in the univariate analysis but not in the multivariate analysis $(\mathrm{p}=0.38$ and 0.095 , respectively; Table 6). The mean preoperative $\mathrm{OHI}$ in those patients requiring a single shunt revision was 0.73 , compared with 0.65 in patients with multiple shunt revisions. In contrast, the mean FOIR value was lower (0.74) in patients with a single shunt revision as compared with that in patients with multiple revisions (0.84). Other factors did not have any significant association with shunt revision frequency (Table 3).

\section{Factors Affecting Shunt Revision-Free Survival}

The mean follow-up was 49.9 months (range 1-144 months). Age was a significant factor affecting shunt revision-free survival (Fig. 2). Patients younger than 6 months had significantly less revision-free survival than the patients who were older than 6 months (median survival 10.1 vs 94.1 months, $\mathrm{p}=0.004)$. Similarly, other factors associated with increased revision-free survival were biventriculomegaly, asymmetrical ventriculomegaly, and the presence of PVL on preoperative images; however, the differences were not statistically significant $(\mathrm{p}=0.27,0.11$, 0.15 , respectively).

\section{Discussion}

Radiological imaging has traditionally been considered

TABLE 4. Relation of linear indices and ratios on pre- and postoperative images with the need for shunt revision

\begin{tabular}{lcccc}
\hline \multirow{2}{*}{$\begin{array}{c}\text { Linear Indices } \\
\text { \& Ratios }\end{array}$} & \multicolumn{2}{c}{ Shunt Revision } & $\begin{array}{c}\text { Univariate } \\
\text { p Value }\end{array}$ & $\begin{array}{c}\text { Multivariate } \\
\text { p Value }\end{array}$ \\
\cline { 2 - 5 } Preop & & No & & \\
\hline Evans' index & $0.46(0.01)$ & $0.44(0.01)$ & 0.25 & 0.33 \\
\hline FHI & $0.54(0.01)$ & $0.54(0.02)$ & 0.4 & 0.10 \\
\hline OHI & $0.69(0.01)$ & $0.66(0.02)$ & 0.15 & 0.36 \\
\hline FOHR & $0.56(0.01)$ & $0.53(0.01)$ & 0.18 & 0.97 \\
\hline FOIR & $0.79(0.02)$ & $0.81(0.02)$ & 0.25 & 0.36 \\
\hline Postop & & & & \\
\hline FOHR & $0.48(0.01)$ & $0.47(0.01)$ & 0.38 & 0.21 \\
\hline FOHR reduc- & $13(2.65)$ & $12.1(2.23)$ & 0.39 & 0.22 \\
tion (\%) & & & & \\
\hline
\end{tabular}

Values expressed as mean (standard error of the mean), unless indicated otherwise. 
TABLE 5. Relation of linear indices and ratios on pre- and postoperative images with the interval of shunt revision

\begin{tabular}{ccccc}
\hline & \multicolumn{2}{c}{$\begin{array}{c}\text { Shunt Revision Interval } \\
\text { (from primary surgery) }\end{array}$} & & \\
\cline { 2 - 3 } $\begin{array}{c}\text { Linear Indices } \\
\text { \& Ratios }\end{array}$ & $\begin{array}{c}\text { Early } \\
(<3 \text { mos })\end{array}$ & $\begin{array}{c}\text { Late } \\
(>3 \text { mos })\end{array}$ & $\begin{array}{c}\text { Univariate } \\
\text { p Value }\end{array}$ & $\begin{array}{c}\text { Multivariate } \\
p \text { Value }\end{array}$ \\
\hline Preop & & & & \\
\hline Evans' index & $0.48(0.02)$ & $0.44(0.02)$ & 0.08 & 0.41 \\
\hline FHI & $0.57(0.02)$ & $0.52(0.02)$ & 0.07 & 0.66 \\
\hline OHI & $0.71(0.02)$ & $0.67(0.02)$ & 0.12 & 0.83 \\
\hline FOHR & $0.58(0.02)$ & $0.53(0.02)$ & 0.049 & 0.38 \\
\hline FOIR & $0.81(0.03)$ & $0.77(0.03)$ & 0.20 & 0.39 \\
\hline Postop & & & & \\
\hline FOHR & $0.46(0.02)$ & $0.49(0.02)$ & 0.19 & 0.23 \\
\hline FOHR reduc- & $20.16(3.84)$ & $6.4(3.3)$ & 0.009 & 0.037 \\
tion (\%) & & & & \\
\hline
\end{tabular}

Values expressed as mean (standard error of the mean), unless indicated otherwise.

the most valuable tool for documenting shunt malfunction. The role of CT and/or MRI in this setting is invaluable. A dilated ventricle, whether the same or increased as compared with its appearance on baseline imaging, is usually suggestive of shunt malfunction; however, the reverse does not hold true in all cases. So a nondilated ventricle does not rule out shunt malfunction and mandates further evaluation and clinical correlation with features of raised intracranial pressure (ICP). Other radiological features that can aid diagnosis include PVL and effacement of sulci. There has been increasing concern regarding the frequent use of cranial CT to monitor shunt function given the risks of high-dose radiation to a developing child. Rapid cranial MRI sequences have been developed to reduce the image acquisition time, thus avoiding motion artifacts and the need for sedation. ${ }^{6}$ A few studies have compared the efficacy of these 2 imaging modalities in diagnosing shunt malfunction and have shown that both have nearly equal specificity (89\%-93\% in rapid cranial MRI vs $76 \%-93 \%$ in CT); however, CT does seem to have better sensitivity than MRI (51\%-59\% in rapid cranial MRI vs 53\%-92\% in CT) ${ }^{1,2,22}$

Multiple studies have demonstrated good correlation between ventricular volume and linear indices on CT scans, which include the Evans' index, FHI, FOHR, and the bicaudate index. ${ }^{7,14,17}$ These studies collectively considered FOHR as the best method for measuring both absolute and relative ventricular volumes. The normal value of the FOHR has been measured as 0.37 (99\% CI 0.36-0.38), which is independent of age. ${ }^{14}$ In the present study we also measured $\mathrm{OHI}$ and FOIR because a substantial number of patients had preferential dilation of the occipital horn as compared with the frontal horn. Measuring these indices on preoperative scans gives an estimate of the preoperative ventricular volume and in this study was correlated with the overall shunt outcome. However, FOHR correlates best with relative ventricular volumes and so was measured on the postoperative images as well to estimate the degree of ventricular volume reduction.
TABLE 6. Relation of linear indices and ratios on pre- and postoperative images with the frequency of shunt revision

\begin{tabular}{|c|c|c|c|c|}
\hline \multirow{2}{*}{$\begin{array}{l}\text { Linear Indices } \\
\text { \& Ratios }\end{array}$} & \multicolumn{2}{|c|}{$\begin{array}{c}\text { Shunt Revision } \\
\text { Frequency }\end{array}$} & \multirow{2}{*}{$\begin{array}{l}\text { Univariate } \\
\text { p Value }\end{array}$} & \multirow{2}{*}{$\begin{array}{c}\text { Multivariate } \\
\text { p Value }\end{array}$} \\
\hline & Single & Multiple & & \\
\hline \multicolumn{5}{|l|}{ Preop } \\
\hline Evans' index & $0.45(0.02)$ & $0.47(0.02)$ & 0.22 & 0.46 \\
\hline $\mathrm{FHI}$ & $0.54(0.02)$ & $0.55(0.02)$ & 0.39 & 0.07 \\
\hline $\mathrm{OHI}$ & $0.73(0.02)$ & $0.65(0.02)$ & 0.029 & 0.38 \\
\hline FOHR & $0.57(0.02)$ & $0.54(0.02)$ & 0.24 & 0.98 \\
\hline FOIR & $0.74(0.02)$ & $0.84(0.03)$ & 0.009 & 0.095 \\
\hline \multicolumn{5}{|l|}{ Postop } \\
\hline FOHR & $0.47(0.02)$ & $0.48(0.02)$ & 0.25 & 0.98 \\
\hline $\begin{array}{c}\text { FOHR reduc- } \\
\text { tion (\%) }\end{array}$ & $14.8(3.9)$ & $11.1(3.6)$ & 0.5 & 0.35 \\
\hline
\end{tabular}

Values expressed as mean (standard error of the mean), unless indicated otherwise.

The morphological pattern of ventricles in the radiological studies at the time of initial evaluation usually does not accurately predict the future circumstances of the patient, especially as related to the need for shunt revision. A few studies in the literature have addressed this specific entity and have come up with specific conclusions. Sellin et al. ${ }^{19}$ observed that patients with hydrocephalus initially presenting with ventricular dilation subsequently presented with dilated ventricles in cases of shunt malfunction. Similarly, nondilation at the initial presentation made subsequent presentation with dilated ventricles less likely in cases of shunt obstruction. These authors also observed, though at a low significance level, that distal shunt failures are more often associated with ventricular dilation than proximal obstruction. In the present study ventricular dilation pattern was further categorized into bi- or triventriculomegaly and right-left symmetry. Though not statistically significant, the presence of biventriculomegaly and asymmetrical ventriculomegaly were associated with low shunt revision rates and increased overall shunt revisionfree survival.

The pattern of ventricular size reduction has been shown to be different in patients undergoing ETV rather than shunt placement. St. George et al. ${ }^{20}$ have demonstrated that ventricular volume decreases steadily up to 3-6 months after ETV and then stabilizes, whereas it decreases even after 6 months post-shunt placement. There has been much controversy over whether this change in ventricular volume has any correlation with clinical outcome. Multiple studies in the literature address this issue; however, most are limited to ETV series. Warf et al. compared the neurocognitive outcome in patients undergoing ETV or VP shunt placement and the reduction in ventricular volume as measured by FOHR and found no correlation between the two. ${ }^{21}$ However, in a more recent study these authors suggested that a combination of brain and CSF volumes has a significant effect on overall neurocognitive outcome. ${ }^{10}$ In 1998 Buxton et al. ${ }^{4}$ described the results of ETV in 27 patients under the age of 1 year. Treatment failure occurred 

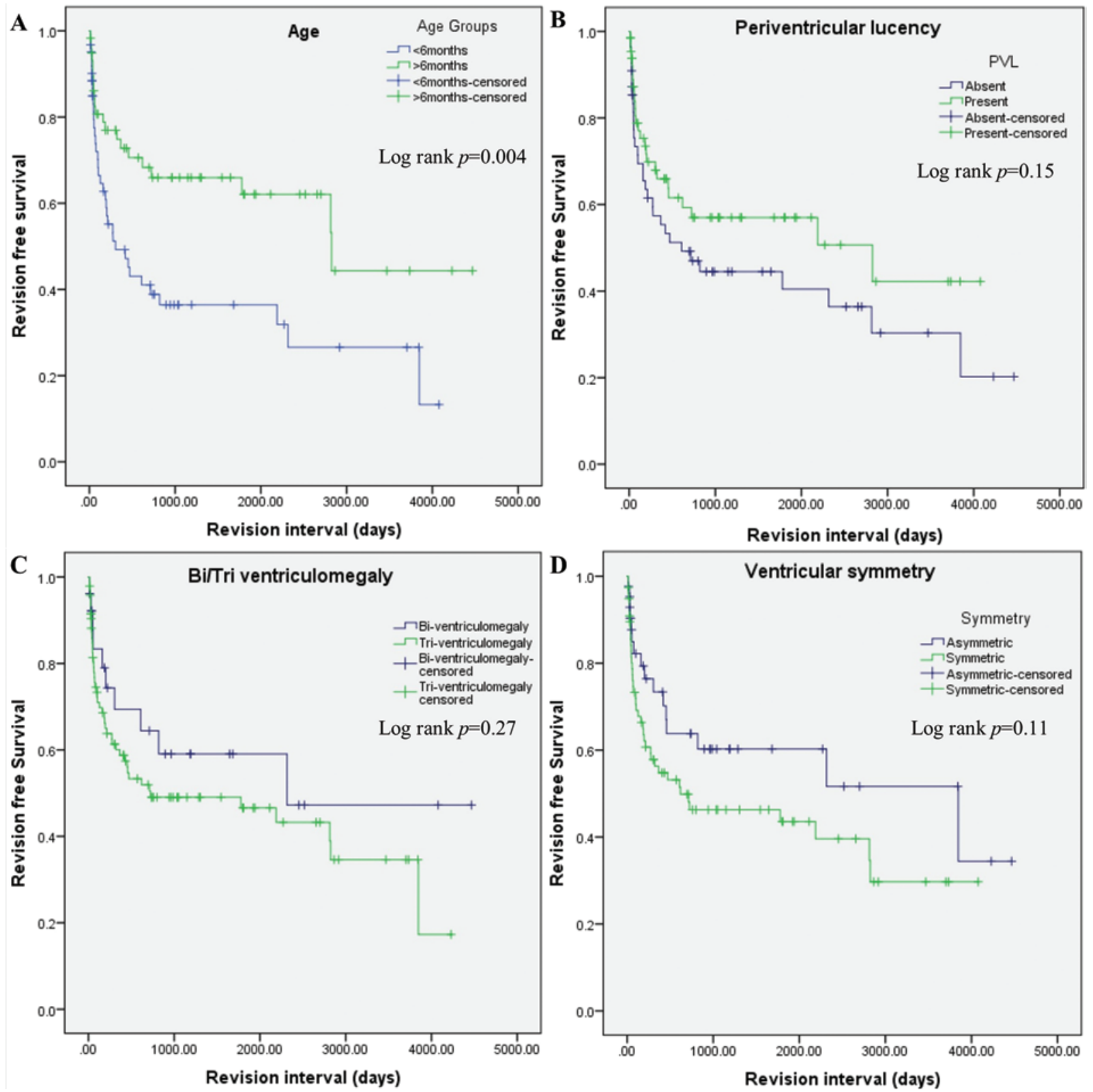

FIG. 2. Kaplan-Meier curves showing differences in revision-free survival in different groups based on age (A), presence of PVL (B), bi- or triventriculomegaly (C), and ventricular symmetry (D).

in $21(78 \%)$ of the patients, and the authors found that the postoperative ventricular size does not correlate with treatment success or failure. In a similar study in 2000, Kim et $a .^{8}$ found that a reduction in ventricular volume does not independently predict clinical outcome. However, in a series of 29 patients undergoing ETV, Kulkarni et al. ${ }^{9}$ showed a significant difference in the degree of ventricular reduction in the patients with clinical success (21 patients, mean FOHR reduction by $16 \%$ ) compared with that in the patients with failure (8 patients, mean FOHR reduction by $7 \% ; \mathrm{p}=0.03 \%$ ). There was no significant association between periventricular edema and clinical success or failure after ETV. However, there was a significant positive correlation between clinical success and the presence of flow voids on sagittal T2-weighted MR images. After a systematic review of all of these studies in 2014, Nikas et al. ${ }^{12}$ suggested that there is insufficient evidence to consider the degree of ventricular reduction as a measure of treatment effectiveness after both ETV and shunt placement. A similar finding was noted in the present study, with no correlation between preoperative radiological indices and a requirement for shunt revision; however, the presence of PVL, which indirectly suggests an acute hypertensive state, ${ }^{11}$ had a lower revision rate. This suggests that ventricular pressure reduction is probably more important than volume reduction to achieve a successful shunt outcome.

The most striking and new finding in the current study was related to the shunt revision interval and shunt revi- 
sion frequency. The reduction in the FOHR was interestingly high in patients who required early shunt revision. This paradoxical finding is probably related to the fact that CSF overdrainage leads to CSF stasis and a greater chance of mechanical shunt obstruction. ${ }^{3}$ Most of the shunts that are routinely used are pressure regulated. A compliant ventricular wall causes rapid decompression of the ventricle, leading to subsequent flow reduction and shunt hardware blockage. However, a less compliant ventricle does not rapidly decrease in size after shunt placement, although a similar reduction in pressure is achieved. This causes less adhesion of the ventricular catheter to the wall and blockage. Note that at this stage this can only be considered a possible hypothesis that needs dynamic studies for further validation. Nevertheless, it possibly carries an important therapeutic implication in that keeping the pressure setting at higher levels when inserting programmable shunts may promote better shunt functioning by avoiding collapse of the ventricles. This further substantiates the fact that one should aim for a ventricular decompression just enough to alleviate the raised ICP rather than an appealing reduction in ventricular size. Another important finding was that greater occipital horn dilation is associated with a lower frequency of shunt revision as dictated by a high $\mathrm{OHI}$ and low FOIR in patients with a single shunt revision as compared with those requiring multiple shunt revisions. However, it is worth mentioning again that these indices do not predict the need for shunt revision itself. In a recent multicenter prospective study, Riva-Cambrin et al..$^{18}$ found that an age $<6$ months is an independent risk factor for shunt failure and an important determinant of shunt survival. Similarly, we found that patients younger than 6 months had significantly fewer days of revision-free survival than their older peers. None of the indices or ventricular characteristics had a significant influence on revision-free survival.

This study has limitations inherent to its retrospective nature. The exclusion of 47 patients because of the unavailability of comparative radiological images may have had some influence on the final outcome. Moreover, the variability in the follow-up also seems to have affected overall revision-free survival. Similarly, the variability in the CT interval had a significant effect on postoperative ventricular indices because of the dynamic nature of CSF drainage through the shunt. These factors can be eliminated by a prospective study with strict clinical and radiological follow-up. In addition, an increase in the sample size may further validate the findings.

\section{Conclusions}

Preoperative radiological linear indices and ratios do not predict the likelihood of subsequent shunt malfunction. However, patients who required early shunt revision $(<90$ days) tended to have greater reductions in ventricular volumes (as measured by a reduction in FOHR) on postoperative images than those who required late revisions. This finding indicates that a greater reduction in ventricular volume is not actually desirable and that a ventricular volume high enough to reduce ICP should be the goal to achieve better long-term shunt compliance.

\section{References}

1. Boyle TP, Nigrovic LE: Radiographic evaluation of pediatric cerebrospinal fluid shunt malfunction in the emergency setting. Pediatr Emerg Care 31:435-443, 2015

2. Boyle TP, Paldino MJ, Kimia AA, Fitz BM, Madsen JR, Monuteaux MC, et al: Comparison of rapid cranial MRI to CT for ventricular shunt malfunction. Pediatrics 134:e47-e54, 2014

3. Browd SR, Ragel BT, Gottfried ON, Kestle JR: Failure of cerebrospinal fluid shunts: part I: Obstruction and mechanical failure. Pediatr Neurol 34:83-92, 2006

4. Buxton N, Macarthur D, Mallucci C, Punt J, Vloeberghs M: Neuroendoscopic third ventriculostomy in patients less than 1 year old. Pediatr Neurosurg 29:73-76, 1998

5. Durfee SM, Kim FM, Benson CB: Postnatal outcome of fetuses with the prenatal diagnosis of asymmetric hydrocephalus. J Ultrasound Med 20:263-268, 2001

6. Iskandar BJ, Sansone JM, Medow J, Rowley HA: The use of quick-brain magnetic resonance imaging in the evaluation of shunt-treated hydrocephalus. J Neurosurg 101 (2 Suppl):147-151, 2004

7. Jamous M, Sood S, Kumar R, Ham S: Frontal and occipital horn width ratio for the evaluation of small and asymmetrical ventricles. Pediatr Neurosurg 39:17-21, 2003

8. Kim SK, Wang KC, Cho BK: Surgical outcome of pediatric hydrocephalus treated by endoscopic III ventriculostomy: prognostic factors and interpretation of postoperative neuroimaging. Childs Nerv Syst 16:161-169, 2000

9. Kulkarni AV, Drake JM, Armstrong DC, Dirks PB: Imaging correlates of successful endoscopic third ventriculostomy. J Neurosurg 92:915-919, 2000

10. Mandell JG, Kulkarni AV, Warf BC, Schiff SJ: Volumetric brain analysis in neurosurgery: Part 2. Brain and CSF volumes discriminate neurocognitive outcomes in hydrocephalus. J Neurosurg Pediatr 15:125-132, 2015

11. Mori K, Handa H, Murata T, Nakano Y: Periventricular lucency in computed tomography of hydrocephalus and cerebral atrophy. J Comput Assist Tomogr 4:204-209, 1980

12. Nikas DC, Post AF, Choudhri AF, Mazzola CA, Mitchell L, Flannery AM: Pediatric hydrocephalus: systematic literature review and evidence-based guidelines. Part 10: Change in ventricle size as a measurement of effective treatment of hydrocephalus. J Neurosurg Pediatr 14 (Suppl 1):77-81, 2014

13. Notarianni C, Vannemreddy P, Caldito G, Bollam P, Wylen $\mathrm{E}$, Willis B, et al: Congenital hydrocephalus and ventriculoperitoneal shunts: influence of etiology and programmable shunts on revisions. J Neurosurg Pediatr 4:547-552, 2009

14. O'Hayon BB, Drake JM, Ossip MG, Tuli S, Clarke M: Frontal and occipital horn ratio: A linear estimate of ventricular size for multiple imaging modalities in pediatric hydrocephalus. Pediatr Neurosurg 29:245-249, 1998

15. Patwardhan RV, Nanda A: Implanted ventricular shunts in the United States: the billion-dollar-a-year cost of hydrocephalus treatment. Neurosurgery 56:139-145, 2005

16. Piatt JH Jr, Carlson CV: A search for determinants of cerebrospinal fluid shunt survival: retrospective analysis of a 14-year institutional experience. Pediatr Neurosurg 19:233242, 1993

17. Ragan DK, Cerqua J, Nash T, McKinstry RC, Shimony JS, Jones BV, et al: The accuracy of linear indices of ventricular volume in pediatric hydrocephalus: technical note. J Neurosurg Pediatr 15:547-551, 2015

18. Riva-Cambrin J, Kestle JR, Holubkov R, Butler J, Kulkarni $\mathrm{AV}$, Drake J, et al: Risk factors for shunt malfunction in pediatric hydrocephalus: a multicenter prospective cohort study. J Neurosurg Pediatr 17:382-390, 2016

19. Sellin JN, Cherian J, Barry JM, Ryan SL, Luerssen TG, Jea A: Utility of computed tomography or magnetic resonance imaging evaluation of ventricular morphology in suspected 
cerebrospinal fluid shunt malfunction. J Neurosurg Pediatr 14:160-166, 2014

20. St George E, Natarajan K, Sgouros S: Changes in ventricular volume in hydrocephalic children following successful endoscopic third ventriculostomy. Childs Nerv Syst 20:834-838, 2004

21. Warf B, Ondoma S, Kulkarni A, Donnelly R, Ampeire M, Akona J, et al: Neurocognitive outcome and ventricular volume in children with myelomeningocele treated for hydrocephalus in Uganda. J Neurosurg Pediatr 4:564-570, 2009

22. Yue EL, Meckler GD, Fleischman RJ, Selden NR, Bardo DM, Chu O'Connor AK, et al: Test characteristics of quick brain MRI for shunt evaluation in children: an alternative modality to avoid radiation. J Neurosurg Pediatr 15:420 426, 2015

\section{Disclosures}

The authors report no conflict of interest concerning the materials or methods used in this study or the findings specified in this paper.

\section{Author Contributions}

Conception and design: Patra, Bir, Maiti, Notarianni. Acquisition of data: Patra, Bir, Maiti, Kalakoti. Analysis and interpretation of data: Patra, Bir, Maiti, Kalakoti. Drafting the article: Patra, Bir, Maiti. Critically revising the article: all authors. Reviewed submitted version of manuscript: all authors. Approved the final version of the manuscript on behalf of all authors: Nanda. Statistical analysis: Patra, Bir, Kalakoti. Administrative/technical/material support: Nanda. Study supervision: Nanda, Cuellar-Saenz, Sun, Guthikonda, Notarianni.

\section{Supplemental Information \\ Videos}

Video abstract. https://vimeo.com/185817544.

\section{Correspondence}

Anil Nanda, Department of Neurosurgery, LSU HealthShreveport, 1501 Kings Hwy., Shreveport, LA 71130-3932. email: ananda@1suhsc.edu. 